\title{
Asymmetric cross-sectional dispersion in stock returns: Evidence and implications
}

\author{
Gregory R. Duffee* \\ Haas School of Business \\ U.C. Berkeley \\ Visiting Scholar, Federal Reserve Bank of San Francisco
}

This Draft: January 2, 2001

\begin{abstract}
This paper documents that daily stock returns of both firms and industries are more dispersed when the overall stock market rises than when it falls. This positive relation is conceptually distinct from-and appears unrelated to-asymmetric return correlations. I argue that the source of the relation is positive skewness in sector-specific return shocks. I use this asymmetric behavior to explain a previously-observed puzzle: Aggregate trading volume tends to be higher on days when the stock market rises than when it falls. The idea proposed here is that trading is more active on days when the market rises because on those days, there is more non-market news on which to trade. I find that empirically, the bulk of the relation between volume and the signed market return is explained by variations in non-market volatility.
\end{abstract}

${ }^{*}$ I thank Maureen O'Hara and seminar participants at the Federal Reserve Board for comments on an earlier draft. The most recent version of this paper is at www.haas.berkeley.edu/ duffee. Contact information: 510-642-1435, duffee@haas.berkeley.edu. The views expressed in this paper are the author's and do not necessarily reflect the views of the Federal Reserve Bank of San Francisco or the Federal Reserve System. 


\section{Introduction}

I document that on days when the U.S. stock market rises, there is greater dispersion among firms' and industries' stock returns than on days when the market falls. In other words, the volatility of non-market components of firms' and industries' stock returns - roughly, idiosyncratic volatility - is higher on days when the overall market goes up. To give a flavor of the results, the volatility of the non-market component of industry-level stock returns is six percent higher on a day when the market rises one percent than on a day when the market falls one percent.

This result is superficially similar to the behavior of correlations among stock returns. Earlier research concluded that correlations among aggregate stock returns in different countries tend to be higher when markets fall than when markets rise, a pattern termed asymmetric correlations. ${ }^{1}$ Ang and Chen (2000) find the same pattern with portfolios of U.S. stocks.

However, the relation between asymmetric return correlations and asymmetric nonmarket volatility is not straightforward. Consider returns to two industries (or firms), $r_{1}$ and $r_{2}$, and the return to the entire stock market, $r_{M}$. To make this example as simple as possible, all returns are mean zero, and industry-level returns consist of a common factor and an idiosyncratic factor,

$$
r_{i}=F_{c}+F_{i}, \quad i=1,2 \text {. }
$$

Their correlation, conditioned on some information $\Omega$, is

$$
\operatorname{Cor}\left(r_{1}, r_{2} \mid \Omega\right)=\frac{\operatorname{Var}\left(F_{c} \mid \Omega\right)}{\operatorname{Var}\left(F_{c} \mid \Omega\right)+\operatorname{Var}\left(F_{i} \mid \Omega\right)} .
$$

Asymmetric return correlations are produced if either $\operatorname{Var}\left(F_{c} \mid r_{M}<0\right)>\operatorname{Var}\left(F_{c} \mid r_{M}>0\right)$ or $\operatorname{Var}\left(F_{i} \mid r_{M}>0\right)>\operatorname{Var}\left(F_{i} \mid r_{M}<0\right)$. The main point of this paper is to document that the latter inequality is observed in U.S. stock return data. Thus in principle, asymmetric non-market volatility could produce the asymmetric correlations observed in Ang and Chen (2000). But researchers, especially in the literature on international stock markets, have typically focused their interpretations of asymmetric correlations on the behavior of $\operatorname{Var}\left(F_{c}\right)$. For example, Das and Uppal (1999) assume that a common factor can periodically jump. If the mean jump size is negative, correlations in down markets can be higher than correlations in up markets. This emphasis on common shocks in explaining correlations in international

\footnotetext{
${ }^{1}$ The literature apparently began with Erb, Harvey, and Viskanta (1994). Additional evidence and references are in Longin and Solnick (2000) and Ang and Bekaert (1999).
} 
stock markets is not unreasonable, given the recent behavior of these markets. The wellknown negative skewness of aggregate U.S. stock market returns is also consistent with a model in which common shocks occasionally exhibit downward jumps. ${ }^{2}$

Why is non-market volatility higher when the overall market rises? I argue that this pattern is a consequence of positive skewness in 'business-sector' news. I use this term to refer to news that is big enough to affect the overall return to the market, but primarily affects only a fraction of firms. Positive skewness in business-sector news is consistent with the fact that non-market components of industry-level and firm-level stock returns tend to be positively skewed. ${ }^{3}$ At the firm level, this was established in Duffee (1995); more recent evidence is in Chen, Hong, and Stein (1999). Positive skewness at the industry level is documented here.

With this pattern of skewness, a large positive return to the aggregate stock market is more likely to be generated by simultaneous positive shocks to a variety of business sectors, while a large negative return is more likely to be generated by a negative common shock. Because sector shocks have heterogeneous effects on different industries and firms, nonmarket volatility is higher on days when the overall market rises than when it falls.

This result suggests that earlier explanations for asymmetric return correlations, which focused on $\operatorname{Var}\left(F_{c}\right)$ instead of $\operatorname{Var}\left(F_{i}\right)$, may be misguided. Because this paper does not explicitly look at return correlations, its evidence on this issue is indirect. I construct a simple model of firm and industry stock returns that allows for positively-skewed sector shocks and negatively-skewed common shocks. The model is calibrated to reproduce the observed negative skewness in daily aggregate stock returns, the positive skewness in the non-market components of industry-level and firm-level stock returns, and the positive relation between the aggregate stock return and measures of non-market volatility. We can then ask what drives asymmetric correlations in the U.S. equity market. The calibration exercise suggests that the primary driver is an asymmetric common factor. Thus asymmetric correlations and asymmetric non-market volatility appear to be largely unrelated.

The positive relation between the market return and non-market volatility can help explain a heretofore puzzling stylized fact: Stock market trading volume is higher when the overall market rises than when the overall market falls. This relation was documented in the literature ten to fifteen years ago, and related evidence is presented here. The point estimates in this paper imply that stock market turnover is roughly five percent higher on

\footnotetext{
${ }^{2}$ Skewness in the aggregate stock market is examined in French, Schwert, and Stambaugh (1987), Harvey and Siddique (1999, 2000), and Campbell and Hentschel (1992).

${ }^{3}$ The term 'skewness' is used imprecisely here. It refers to the contemporaneous relation between the sign of a shock and some measure of the volatility of the shock, rather than a precise statement about the third central moment of the factor.
} 
days when the market rises one percent than on days when the market falls one percent. Existing attempts to explain this pattern are largely ad hoc.

I argue that this relation is driven primarily by greater news arrival on days when the market rises. The volatility of the non-market components of firms' stock returns proxies for the amount of non-market news that has arrived. On days when the market rises, there is more news, thus traders are more active. This hypothesis is confirmed here. Holding non-market volatility constant, the bulk of the positive relation between trading volume and the market return disappears.

The outline of the remainder of this paper is as follows. Section 2 defines some measures of non-market volatility and documents the positive relation between these measures and market returns. Section 3 attempts to explain these results with a multifactor model of stock returns. Section 4 considers the links among trading volume, market returns, and dispersion. Some concluding comments are contained in the final section.

\section{The empirical evidence}

The objective of this section is to describe the empirical relation between the return to the overall stock market and non-market stock return volatility. Thus we begin by measuring stock returns and calculating measures of return volatility.

\section{$2.1 \quad$ The data}

The data are daily returns to securities included on the Center for Research in Security Prices (CRSP) NYSE/Amex/Nasdaq file. The analysis is restricted to common stocks of domestic firms. (Securities with CRSP sharecodes of 10 or 11 over their entire sample.) The sample period is July 1962 through December 1999. I use the daily return to the CRSP value-weighted index to measure aggregate stock returns.

\subsection{Measuring non-market volatility}

To construct measures of non-market volatility, I first construct non-market shocks to firms' stock returns. I follow Campbell, Lettau, Malkiel, and Xu (2000) by constructing both industry-specific and firm-specific shocks using a market model. Each common stock on the CRSP tape is assigned to a single industry based on its most recent four-digit SIC code on the CRSP tape. The 49-industry breakdown in Campbell et al. (2000) is used, which was originally adopted by Fama and French (1997). Each time series of industry-level stock returns is constructed by value-weighting the raw stock returns of the firms that belong 
to the industry. ${ }^{4}$ Non-market stock return shocks are constructed using a market model. Denote the log return to the aggregate stock market from the end of day $t-1$ to the end of day $t$ as $r_{M, t}$. The log return to industry $i$ on the same date is denoted $r_{i, t}$. Because daily returns to stock portfolios are positively serially correlated I include lags of both returns in the market model equation.

$$
r_{i, t}=\alpha_{i}+\beta_{1, i, t} r_{M, t}+\beta_{2, i, t} r_{M, t-1}+\beta_{3, i, t} r_{i, t-1}+\epsilon_{i, t}
$$

A similar approach is taken to constructing firm-specific return shocks. Denote the log stock return to firm $k$ as $r_{k, t}$ and the industry to which the firm belongs as $i_{k}$. Firm returns are assumed to be related to both the market return and the return to the industry $i_{k}$.

$$
r_{k, t}=\alpha_{k}+\beta_{1, k, t} r_{M, t}+\beta_{2, k, t} r_{M, t-1}+\beta_{3, k, t} r_{i_{k}, t}+\beta_{4, k, t} r_{i_{k}, t-1}+\beta_{5, k, t} r_{k, t-1}+\epsilon_{k, t}
$$

It is important to note that there is no requirement that the residuals in (1) and (2) are independent across firms or industries. In fact, as we will see in the next section's model, nonzero cross-correlations among the residuals are important in reproducing the behavior of the volatilities of these residuals. Therefore I avoid the term 'idiosyncratic.' Instead, I refer to these residuals as the non-market components of firm-level and industry-level returns. This terminology is slightly misleading because the firm-level residuals are not only non-market, but also non-industry- $i_{k}$.

Because the coefficients in (1) and (2) are unknown, we cannot observe $\epsilon_{i, t}$ and $\epsilon_{k, t}$ directly. I estimate them by treating the equations as regressions. I implement these regressions in two ways. To illustrate these methods, consider the firm-level equation (2). The first method estimates (2) over the entire sample of a firm's returns and produces the series $\hat{\epsilon}_{k, t}$ as a residual. This regression is estimated for each individual security that has a minimum of 500 days for which both $r_{k, t}$ and $r_{k, t-1}$ are not missing.

The second method uses rolling regressions to construct $\hat{\epsilon}_{k, t}$ out of sample. Rolling regressions are estimated for each security with at least 501 days for which $r_{k, t}$ and $r_{k, t-1}$ are not missing. Each rolling regression is estimated using 500 observations, or about two years of daily returns. The resulting coefficient estimates are used to produce out-of-sample observations of $\hat{\epsilon}_{k, t}$ for the next 60 days. (Or fewer, if there are fewer than 60 remaining days for which security $k$ has non-missing returns.) The same two methods are used to construct

\footnotetext{
${ }^{4}$ All value-weighted series in this paper use day $t-1$ market capitalizations to weight day $t$ firm-level values.
} 
industry-level return shocks.

I measure daily non-market volatility with value-weighted absolute residuals. The formulas are

$$
\begin{gathered}
I N D_{t}=\sum_{i=1}^{49} \omega_{i, t}\left|\hat{\epsilon}_{i, t}\right|, \\
F I R M_{t}=\sum_{k=1}^{N_{t}} \omega_{k, t}\left|\hat{\epsilon}_{k, t}\right| .
\end{gathered}
$$

The weights $\omega_{i, t}$ and $\omega_{k, t}$ are day $t-1$ market capitalizations and $N_{t}$ is the number of securities for which $\hat{\epsilon}_{k, t}$ is not missing. The in-sample measures of $I N D_{t}$ and FIRM $M_{t}$ are defined from July 3, 1962 through December 31, 1999. Over this period, $N_{t}$ ranges from 1787 to 7240 securities, with a median value of 4832. The out-of-sample measures of $I N D_{t}$ and FIRMt begin with June 30, 1964, and $N_{t}$ ranges from 1109 to 5856 securities, with a median of 4319 .

Absolute residuals are used in (3) and (4) instead of squared residuals because the daily stock returns have very fat tails. ${ }^{5}$ Davidian and Carroll (1987) and Schwert and Seguin (1990) conclude that measures that use squared residuals tend to be sensitive to outliers. Later in this section I discuss differences that result with the use of squared residuals.

Summary statistics for these measures of non-market volatility are reported in Table 1, while Figure 1 displays the time series. To conserve space, statistics are reported for only the in-sample measures. The in-sample and out-of-sample measures of volatility are almost identical. The correlation between $F I R M_{t}$ calculated with in-sample residuals and $F I R M_{t}$ calculated with out-of-sample residuals is 0.992 . The corresponding correlation for $I N D_{t}$ is 0.968. Because there is essentially no information in the out-of-sample measures that is not also in the in-sample measures, and because the in-sample measures are available over a longer time series, in the remainder of the paper I focus exclusively on the in-sample measures.

Table 1 documents that daily value-weighted absolute industry-level residuals averaged about 0.4 percent over the entire sample. Absolute firm-level residuals averaged 1.0 percent over the same period. Non-market volatility has risen over time, as observed by Campbell

\footnotetext{
${ }^{5}$ Averages of squared daily returns can be used to estimate longer-horizon volatilities along the lines of Campbell et al. (2000), who follow French et al. (1987). The averaging of the daily data deemphasizes the fat tails in daily returns.
} 
et al. (2000). For example, the mean absolute firm-level residual rose from just over 0.9 percent through 1979 to 1.1 percent after 1979. Figure 1 confirms the general upward trend in non-market volatility, and illustrates that the $I N D_{t}$ and $F I R M_{t}$ tend to move together over time. Over the entire sample, the correlation between these series is 0.77 .

The figure also shows that non-market volatility peaked during the period surrounding the October 1987 stock market crash. This is not surprising, given the evidence in Campbell et al. (2000) that non-market volatility and the volatility of the market move together. The final point to note about these volatility series is that they are persistent. The $\operatorname{AR}(1)$ coefficient is 0.61 for the log of industry-level volatility and 0.87 for the log of firm-level volatility.

\subsection{The relation between the market return and non-market volatil- ity}

To investigate the contemporaneous relation between non-market volatility and the return to the market, I estimate (5) with ordinary least-squares (OLS).

$$
\begin{gathered}
\log \left(V_{t}\right)=b_{0}+b_{1} r_{M, t}+b_{2}\left|r_{M, t}\right|+\sum_{i=1}^{10}\left[b_{2+i} r_{M, t-i}+b_{12+i}\left|r_{M, t-i}\right|+b_{22+i} \log \left(V_{t-i}\right)\right]+e_{t} ; \\
V_{t}=\left\{\begin{array}{l}
I N D_{t} \\
F I R M_{t} .
\end{array}\right.
\end{gathered}
$$

The log of volatility is used as the dependent variable because each time series has a few large outliers that might disproportionately affect the results. This is especially a concern because the outliers are concentrated around the October 1987 crash, when the right-handside variables were also outliers. As seen in Figure 1, the log transformation produces time series that are better behaved. The coefficients of interest in (5) are those on $r_{M, t}$ and $\left|r_{M, t}\right|$. They allow for non-market volatility to have an asymmetric relationship with the contemporaneous market return. We can think of $b_{2}+b_{1}$ as the relation between non-market volatility and the absolute market return when the market return is positive, while $b_{2}-b_{1}$ measures the same relation when the market return is negative. The lags in (5) are used to pick up the high persistence of both non-market volatility and $\left|r_{M, t}\right|$. Experimentation indicated that the number of lags has little effect on the coefficients of interest, as long as at least two days of lags are included.

It should be emphasized that (5) implies nothing about causation. In particular, day t's 
market return does not determine the amount of non-market volatility on day $t$. Presumably both are driven by a stochastic process that determines the amount of information revealed each day about firms, industries, and the macroeconomy. The regression equation is simply a tool to draw some inferences about this underlying process.

I estimate (5) for both industry-level and firm-level non-market volatility, where in-sample residuals are used to construct the volatility measure. The sample period is July 3, 1962 through December 31, 1999. To get a sense for the time-variation in the relationship between market returns and non-market volatility, I also estimate the regression over each decade's observations. The results are displayed in Table 2. Panels A and B report results for industry-level and firm-level non-market volatility, respectively.

There are two major points to take away from this table. First, non-market volatility is higher when the market rises. For example, the point estimates from the full-sample regressions imply that industry-level volatility is six percent higher (log volatility is 0.061 higher) when the market rises one percent than when the market falls one percent. The full-sample results for firm-level volatility are similar. Firm-level volatilty is almost three percent higher when the market rises one percent than when the market falls one percent. The standard errors, which are corrected for generalized heteroskedasticity, indicate that the statistical strength of this positive relation is overwhelming for all but the industry-level results in the 1990s subperiod.

There is another way to interpret the coefficients in Table 2. As noted above, the 'responsiveness' (in a regression sense) of non-market volatility to the market's absolute return is $b_{2}+b_{1}$ when the market goes up and $b_{2}-b_{1}$ when the market goes down. The ratio of these sums can be viewed as the relative amount of asymmetry between non-market volatility and the market's return. The full-sample results indicate that this ratio is around 1.5 at the industry level and 1.4 at the firm level.

The second major point is that the strength of the relation between non-market volatility and the market's return (both signed and absolute) has declined steadily over time. For each measure of volatility, the estimated coefficients $b_{1}$ and $b_{2}$ both fall (almost) monotonically from the 1960s to the 1990s. Over this period the firm-level and industry-level estimates of $b_{1}$ and $b_{2}$ fall by more than one-half. The decline in both $b_{1}$ and $b_{2}$ produces no clear pattern over time in the behavior of $\left(b_{2}+b_{1}\right) /\left(b_{2}-b_{1}\right)$. For industry-level volatility, this ratio is highest in the 1980s and lowest in the 1990s. For firm-level volatility, the ratio is highest in the 1960s and lowest in the 1990s.

In Section 3, a multifactor model of stock returns is presented to explain the patterns documented here. Before turning to the model, however, a closer look at the relation between the market's return and non-market volatility will be helpful. 


\subsection{Additional evidence}

Here I ask two questions about the relation between non-market volatility and the return to the market. First, is the relation driven by a relatively few days on which the market dramatically moves? Second, how persistent is the increase (decrease) in non-market volatility following a increase (decrease) in the market?

I investigate the first question in three ways. First, I split data into two samples based on the size of the absolute market return. The first sample contains the days for which the absolute market return is less than one percent, and the second sample contains all other days. Then (5) is estimated separately over the two samples. The results are displayed in Table 3.

The evidence of Table 3 does not support the view that a few outliers drive the relation between non-market volatility and the market's return. In fact, the relation is stronger for small absolute market returns than for large absolute market returns. At the industry level, $b_{1}$ on a 'quiet' day is 1.6 times as large as it is on a 'big' day. At the firm level, this ratio exceeds 2.5 .

Table 3 looked at whether market outliers were responsible for the empirical relation in Table 2. Our second look at outliers asks whether firm-level or industry-level outliers are responsible for the result. To investigate this question, I redefined non-market volatility. Instead of using mean absolute residuals, as in (3) and (4), I used the standard deviation of value-weighted residuals. Because this alternate method uses squared residuals instead of absolute residuals, it magnifies the impact of outlying residuals. In results that are not detailed here, I found that switching to this definition weakened the positive relation between the market return and non-market volatility.

Our third look at outliers uses subsample regressions. The period from July 5, 1962 through December 29, 1999 is broken up into 214 periods, each of length 44 trading days. Over each period, a slight variant of (5) is estimated; the only alteration to the equation is to use two lags instead of ten, to reduce the degrees of freedom relative to the number of data points. Table 4 reports summary statistics for the 214 estimated coefficients on the market return and the absolute market return. The table documents that in the large majority of these two-month periods, a positive market return corresponds to higher nonmarket volatility at both the industry and firm levels. Put differently, the positive relation between non-market volatility and the market is not driven by a few periods of extreme behavior. Instead, the relation is a consistent feature of stock returns.

The parameters from the regression equation (5) tells us that non-market volatility rises

on days when the aggregate market rises. I now investigate the persistence of this positive relation. If, say, the aggregate market rises one percent on day $t$, is non-market volatility 
on day $t+i, i>0$, typically higher than if the market falls one percent on day $t$ ? Before attempting to answer this question empirically, it is worth looking at what earlier results in the literature would lead us to conclude.

It is well-known that stock market volatility is persistent. For example, Campbell et al. (2000) find that aggregate volatility, non-market industry-level volatility, and non-market firm-level volatility all have long-lived components. This fact suggests that the high nonmarket volatility on day $t$ (corresponding to a positive market return on day $t$ ) dies off slowly, resulting in high non-market volatility on day $t+i$ as well. However, there is another effect that works in the opposite direction. A large literature starting with Black (1976) has documented a negative correlation between market returns and future market volatility (often called the leverage effect). In addition, Campbell et al. (2000) find that firm-level, industry-level, and market-level volatilities all move together over time. The combination of these latter two facts suggests that non-market volatility on day $t+i$ will be lower after a positive return on day $t$ than after a negative return on day $t$. The positive return predicts lower future aggregate volatility, which corresponds to lower future non-market volatility. The net effect on day $t+i$ non-market volatility is unclear.

I investigate persistence using a set of regressions based on (5), where the dependent variable ranges from the contemporaneous log non-market volatility to twenty-day-ahead log non-market volatility. The regression equation is

$$
\begin{aligned}
\log \left(V_{t+i}\right)= & b_{i, 0}+b_{i, 1} r_{M, t}+b_{i, 2}\left|r_{M, t}\right| \\
& +\sum_{j=1}^{10}\left[b_{i, 2+j} r_{M, t-j}+b_{i, 12+j}\left|r_{M, t-j}\right|+b_{i, 22+j} \log \left(V_{t-j}\right)\right]+e_{i, t+i}, i=1, \ldots, 20,
\end{aligned}
$$

for $V_{t}=\left\{F I R M_{t}, I N D_{t}\right\}$. The sample period is July 3, 1962 through December 31, 1999. Information about the estimated coefficients is displayed in Figure 2. Panels A and B in the figure refer to industry-level and firm-level non-market volatility, respectively.

The lines with "+" in Figure 2 plot the sum $b_{1}+b_{2}$. The sum represents the percentage change in volatility for a one percent absolute market return, where the return is positive. The lines with "-" plot the difference $b_{2}-b_{1}$, which represents the corresponding percentage change in volatility for a negative one percent market return. (The baseline is a zero market return.) It is clear from the figure that the higher non-market volatility that accompanies a positive market return quickly dies away. After day $t+1$, non-market volatility is lower following a day- $t$ positive return than following a day- $t$ negative return. Thus whatever drives the positive contemporaneous relation is very short-lived. The model of Section 3 
produces such a short-lived pattern.

\subsection{Can this pattern be explained with time-varying conditional moments?}

There are two types of models of stock returns that produce an asymmetric relation between stock returns and stock return volatility. One has symmetric shocks and asymmetric timevariation in conditional moments, and the other has asymmetric shocks. Here I take a brief look at the first type. The second is examined in the next section.

The main idea is that stock returns have symmetric conditional distributions, but the conditional expectation of the market's return covaries with conditional non-market volatility. This is the spirit of the regime-switching GARCH model in Ang and Chen (2000). We can envision a return-generating process that switches between a state characterized by high expected returns and high non-market volatility, and a state characterized by the reverse pattern.

This model is not a compelling interpretation of non-market volatility in the U.S. stock market. Recall the results in Table 4, which looked at the relation between market returns and non-market volatility over two-month periods. Breaking up the entire sample period into many subsamples should attenuate the effect of time-varying conditional moments, because over a small time period the variation in the conditional moments should be small relative to size of the shocks. But in the table, we see that breaking up the sample period results in a higher mean coefficient that the coefficient reported in Table 2. In addition, Figure 2 tells us the increase in non-market volatility on a day when the market rises is not persistent, which is inconsistent with a regime-switching story. More directly, we can simply look at the ability of non-market volatility to predict one-day-ahead market returns. In results not detailed here, I find that the predictive ability is not statistically significant for either industry-level or firm-level non-market volatility. ${ }^{6}$ Some other explanation is needed to account for the positive relation between the market's return and non-market volatility.

\footnotetext{
${ }^{6}$ There is a caveat to this result. When day $t$ 's aggregate market stock return is regressed on both day $t-1$ 's aggregate stock market return and day $t-1$ 's $\log$ non-market volatility, the coefficient on volatility is statistically indistinguishable from zero at typical confidence intervals. If, however, the lagged aggregate market return is excluded from the regression, the result changes. Recall that daily aggregate stock market returns are positively autocorrelated. The AR(1) coefficient for the CRSP value-weighted index is approximately 0.17. Because there is a positive contemporaneous relation between the return on the market and non-market volatility, a univariate regression of the market's return on lagged non-market volatility produces a statistically significant positive relation. The reason is that lagged volatility picks up part of the serial correlation.
} 


\section{Skewness}

This section presents a model of stock returns designed to produce a positive relation between the market's return and non-market volatility. The key element of the model is asymmetric distributions of shocks to stock returns. Because there will be many references to asymmetries here, it will be helpful to summarize the three kinds that will appear. They are

1. Asymmetric distributions of returns - roughly, skewness. It is well-known that aggregate market returns are negatively skewed. Less well-known is the fact that returns to individual stocks are positively skewed; see, e.g., Duffee (1995) and Chen, Hong, and Stein (1999).

2. Asymmetry in non-market volatility. As documented in the previous section, nonmarket volatility tends to be higher when the market return is positive.

3. Asymmetry in correlations. Correlations among stock returns tend to be higher when the market return is negative. As noted in the Introduction, earlier research has documented this asymmetry; some additional evidence will be presented later.

These three types of asymmetry are closely related. Because the magnitude of the asymmetry in distributions of shocks to stock returns is important understanding other types, we now take a close empirical look at skewness.

\subsection{Skewness: Evidence}

Here we look at asymmetric distributions of industry-level and firm-level non-market shocks to returns. The shocks are the in-sample residuals calculated with (1) and (2). Two measures of asymmetry in these shocks are calculated. The first is standardized skewness. For firm $k$, it is defined as

$$
S K E W_{k}=\frac{\frac{1}{N_{k}}\left(\sum_{t=1}^{N_{k}} \hat{\epsilon}_{k, t}^{3}\right)}{\left(\frac{1}{N_{k}} \sum_{t=1}^{N_{k}} \hat{\epsilon}_{k, t}^{2}\right)^{3 / 2}}
$$

where $N_{k}$ is the number of days for which the firm has valid stock return residuals. Industry skewness is defined in the same way. One drawback with skewness as a measure of asymmetry is that it is influenced heavily by outliers. Following the logic of Davidian and Carroll (1987), I also measure return asymmetry with absolute residuals. I refer to this measure as 'standardized absolute asymmetry.' 


$$
A B S_{k}=\frac{\frac{1}{N_{k}}\left(\sum_{t=1}^{N_{k}} \hat{\epsilon}_{f, t}\left|\hat{\epsilon}_{f, t}\right|\right)}{\left(\frac{1}{N_{k}} \sum_{t=1}^{N_{k}} \hat{\epsilon}_{f, t}^{2}\right)^{1 / 2}\left(\frac{1}{N_{k}} \sum_{t=1}^{N_{k}}\left|\hat{\epsilon}_{f, t}\right|\right)}
$$

These measures are constructed for each of the 49 time-series of industry-level shocks and for 16,619 time-series of firm-level shocks. Summary statistics are reported in Table 5.

The first row in the table documents the asymmetry in industry-level residuals. The residuals for most industries are weakly positively skewed. The median standardized skewness for the 49 industries is 0.06 , with 28 of the 49 values exceeding zero. The median standardized absolute asymmetry is 0.03 , with 34 of the 49 values exceeding zero. One way to interpret these numbers is to compare them to the corresponding measures for the daily return to the CRSP value-weighted index, which are -1.31 and $-0.11 .^{7}$ Because of the sensitivity of $S K E W$ to outliers, I emphasize $A B S$ as a measure of asymmetry in the remainder of the paper. With this measure, the asymmetry in industry-level residuals is roughly one-fourth (with the opposite sign) of the asymmetry in the market return.

Firm-level residuals are much more positively skewed. The second row in the table documents that the median value of $A B S$ for firm-level residuals is 0.08 . Of the 16,619 firms, 12,280 have positive values of $A B S$. Because the vast majority of these firms are very small, these statistics do not tell us much about the properties of larger firms' return residuals. Therefore I sorted the 5,750 firms in my sample that were on the CRSP tape as of January 1990 into deciles based on their January 1990 market capitalization. The remaining rows in the table report measures of asymmetry for these size-sorted firms. Standardized asymmetry has a nonmonotonic relation with firm size. It is lowest for the firms in the smallest size decile, generally rises through decile eight, then falls for the largest firms. These results are not at odds with earlier work that documents smaller firms have more positively-skewed returns. Although small firm stock returns are more positively skewed, they also more volatile; the net effect is that their standardized asymmetry is smaller than that for large firms.

\subsection{Economic stories for positive skewness}

Chen et al. (1999) note that there are no economic models that have, as a natural implication, positively skewed shocks to industries' or firms' stock returns. They suggest that firms' managers may attempt to hide bad news and trumpet good news. A more fundamentalsbased story seems consistent with the positive skewness in both firm-level and industry-level

\footnotetext{
${ }^{7}$ These values are for residuals to the index, constructed with an in-sample AR(1). The sample period is July 1962 through December 1999.
} 
residuals documented in Table 5. Industry-specific and firm-specific news are positively skewed because news about technological shocks and firms' projects is inherently positively skewed. Either a technological advance is made, or it is not; either a firm finds a positive NPV project, or it doesn't. No news is bad news, because an advance was not made, and a project was not started.

The fundamentals-based story generates positive skewness in industry-level return shocks, while a manager-based story will have difficulty doing so. If news hits an industry, as opposed to a single firm, no one manager can hide the news. The model below relies on positive skewness in sector-specific stock-return shocks, which are most easily interpreted as technology shocks. The model also has a negatively skewed common shock. Again, we can spin stories about this negative skewness (e.g., risk aversion), but the economics that underlie the negative skewness are not essential to understanding the properties of the model.

\subsection{A simple model linking skewness to other asymmetries}

The combination of a negatively-skewed common factor and positively-skewed sector factors will generate a positive relation between the market's return and non-market volatility. For a given absolute market return, a positive return is more likely generated by many positivelyskewed sector shocks, while a negative return is more likely generated by a common factor. The sector shocks will produce more dispersion among stock returns to industries and firms than will a common shock, so non-market volatility is, on average, higher when the market rises.

Both types of shocks also contribute to asymmetric correlations among stock returns. For example, the correlation between the market's return and the return to industry $i$ will be higher when the market's return is negative than when the market's return is positive. The higher downside correlation can be attributed both to the greater likelihood of a large common shock (negative skewness in this shock) and the smaller likelihood of large sector shocks (positive skewness in these shocks).

Here I construct a very simple, stylized mathematical description of stock returns to illustrate these points, and to answer two questions. First, is the magnitude of the skewness we observe in industry-level and firm-level residuals consistent with the magnitude of the observed relation between the market's return and non-market volatility? Second, are asymmetric correlations primarily driven by a negatively-skewed common shock or positivelyskewed sector shocks?

Assume there are $N$ independent sectors in the economy, indexed by $j=1, \ldots, N$. A mimicking portfolio for sector $j$ has a return $F_{j, t}$, which we refer to as a 'sector return.' This 
return will have an expected component and a shock; the shock is denoted $\tilde{F}_{j, t}$.

The sector shock has a Gaussian component and a jump component. In this discrete-time setup, the Bernoulli random variable $Z_{j, t}$ is zero with probability $\left(1-\lambda_{s}\right)$ and is one with probability $\lambda_{s}$. It is independent across time and sectors. The jump probability is the same across sectors, as is the jump size, which is a constant $S_{s}>0$.

$$
\tilde{F}_{j, t}=-S_{s} \lambda_{s}+\epsilon_{j, t}+S_{s} Z_{j, t}, \quad \epsilon_{j, t} \sim N\left(0, \sigma_{s}\right)
$$

In (6), the shock $\epsilon_{j, t}$ is independent across sectors and time. Thus sector return shocks are all drawn from the same distribution, but are independent across sectors. The empirical evidence in the previous section indicated that the relation between the market's return and non-market volatility is not driven by a few large shocks. Accordingly, the frequency of factor jumps is set to $\lambda_{s}=30 / 252$, so the probability that a jump occurs in a given week exceeds $1 / 2$.

There is also a common factor in the stock market. A mimicking portfolio for this common factor has a return $F_{c, t}$ and a shock $\tilde{F}_{c, t}$. The common shock has a Gaussian component $\epsilon_{c, t}$ and a jump component $Z_{c, t}$, where the probability of a jump on any day is $\lambda_{c}$ :

$$
\tilde{F}_{c, t}=-S_{c} \lambda_{c}+\epsilon_{c, t}+S_{c} Z_{c, t}, \quad \epsilon_{c, t} \sim N\left(0, \sigma_{c}\right)
$$

The common random variables are independent of the sector-specific random variables. I set $\lambda_{c}=1.8 / 252$ ), so that less than two common jumps are expected each year.

Firms are indexed by $k$. The stock return to firm $k$ consists of a constant term, the common factor, a single sector factor, and a purely idiosyncratic factor. The notation $j_{k}$ refers to the sector to which firm $k$ is exposed. The return is

$$
r_{k, t}=r_{k}^{e}+\tilde{F}_{c, t}+\tilde{F}_{j_{k}, t}+\zeta_{k, t}, \quad \zeta_{k, t} \sim N\left(0, \sigma_{f}\right)
$$

Industries, which are indexed by $i$, consist of many firms. A key assumption of the model is that the firms in a particular industry are not all exposed to the same economic sector. Industry categories are crude method of sorting, and industries include firms with exposures to a variety of sectors. This assumption implies that when a firm's stock returns are regressed on the market return and the return to the firm's industry, the firm-level residual will not be truly idiosyncratic. This is essential to generate a positive relation between the market 
return and the volatility of this firm-level residual.

This is formalized in the model by assuming that each industry consists of equal exposures to $P$ different sectors, indexed by $j_{l}, l=1, \ldots, P$. A simple way to think of an industry is that it a fraction $1 / P$ of firms exposed to sector $j_{1}$, a fraction $1 / P$ of firms exposed sector

$j_{2}$, and so on. Industry-wide diversification is assumed to wash away the firm-specific shocks $\zeta_{k, t}$. The return to industry $i$ is then

$$
r_{i, t}=r_{i}^{e}+\tilde{F}_{c, t}+(1 / P) \sum_{l=1}^{P} \tilde{F}_{j_{l}, t} .
$$

Sector shocks affect more than one industry. The simple way that this is implemented here is to have as many industries as sectors, $N$. Industry $i$ is exposed to sectors $1+\bmod (i+$ $l-2, N), l=1, \ldots, P$. If we put the industries into a circle, industry $i$ shares exposure to $P-1$ sectors with the two industries next to it in the circle. It shares exposure to $P-2$ sectors with the two industries one step further away, and so on.

The aggregate return to the stock market is an equal-weighted return to the industries:

$$
r_{M, t}=\sum_{i=1}^{N} r_{i, t}
$$

Instead of formally estimating the model, I use simulations to calibrate its parameters. The model is too stylized to do much more with it.

\subsection{Model calibration}

Equations (6) and (7) are simulated to produce a long time series of factor realizations. The number of sectors (and industries) $N$ is set to 50, to approximate the 49 industries examined in Section 2. Equation (8) is then used to construct returns for 550 firms. Each sector has 11 firms that are exposed to it. Industry returns are constructed with $(9)$, setting $P=11$. Market returns are constructed with (10).

Industry-level residuals are produced by regressing industry returns on the market return. Firm-level residuals are produced by regressing firm returns on the firm's industry return and on the market return. Absolute residuals are then averaged (equally-weighted) across industries and firms to produce time series of industry-level and firm-level non-market volatility.

The model's parameters were chosen to roughly fit the following characteristics of actual 
stock returns.

1. The standard deviation of the market return and the mean standard deviations of industry-level and firm-level residuals.

2. The $A B S$ measure of skewness (absolute standardized asymmetry) for the market return and the mean $A B S$ measures for industry-level and firm-level residuals.

3. For both industry-level and firm-level residuals, the coefficient on the market's return from a regression of log non-market volatility on the contemporaneous market return and the absolute value of this return.

4. The correlations, conditional on the sign of the market's return, between the market's return and both industry-level and firm-level returns.

The parameters used to fit these characteristics are $S_{s}=0.05, S_{c}=-0.044, \sigma_{s}=0.022, \sigma_{c}=$ 0.0063 , and $\sigma_{f}=0.02$. These jump sizes mean that about twice every three weeks, a sector has a jump of 5.0 percent, while about twice every three years, the common factor has a jump of -4.4 percent.

Table 6 compares some of the statistical properties of returns generated by the model to the corresponding properties in actual returns. The first three columns report standardized absolute asymmetry for the market as a whole and for the mean industry and firm. The fourth and fifth columns report the coefficient $b_{1}$ from regression equation (5) for industrylevel and firm-level non-market volatility, although the lags are not included in the simulated regressions. (The construction of the model implies that the lags will have no explanatory power.) The next two columns report mean correlations between the market's return and each industry's (or firm's) return, conditioned on a positive market return:

$$
\operatorname{Cor}\left(r_{M, t}, r_{i, t} \mid r_{M, t}>0\right), \quad \operatorname{Cor}\left(r_{M, t}, r_{k, t} \mid r_{M, t}>0\right)
$$

The final two columns report mean correlations conditioned on a negative market return.

The top row of the table reports actual values for 1962 through 1999. The only information in this row not reported in earlier tables are the correlations, which indicate that for the typical industry and firm, the correlation with the market is higher when the market falls than when the market rises. This is consistent with the evidence on equity portfolios in Ang and Chen (2000), and is similar to the evidence on correlations among returns to international equity markets.

Overall, the model qualitatively captures the three kinds of asymmetry that we observe in the data: asymmetry in return shocks, asymmetry in correlations, and asymmetry in nonmarket volatility. The second row of the table reports simulated values for the calibrated 
model. The model reproduces the negative skewness in the market's return and the positive skewness in industry-level and firm-level return residuals. The model is not as successful at matching the asymmetric relationship between the market's return and non-market volatility. It gets the sign of the relationship correct, but the magitudes are too low. The implied $b_{1}$ coefficients on the market return are 2.2 and 1.4 for industry-level and firm-level residuals, respectively, versus 3.0 and 1.5 in the data. The model does reasonably well at reproducing the asymmetric return correlations in the data, although the magnitude of the asymmetry for industry-level returns is larger in the model than it is in the data.

These asymmetries are driven by a combination of negatively skewed common shocks and positively skewed sector shocks. To decompose their respective contributions, the third and fourth rows of the table set the sector jump size and the market jump size to zero, respectively. 8 Without sector jumps, the positive skewness in industry-level and firm-level return residuals disappears, as does the positive relation between the market's return and non-market volatility. However, the difference between upside and downside correlations remains. Without common jumps, the market return is no longer negatively skewed, and the difference between upside and downside correlations largely disappears. Thus these results suggest that the asymmetric correlations we observe in the U.S. equity market are primarily driven by a negatively-skewed commmon shock instead of by positively-skewed sector shocks.

\section{Stock return dispersion and trading volume}

\subsection{A review}

Research on trading volume typically does not use raw trading volume. Volume is usually transformed in some fashion so that the transformed variable is stationary. Denote such a

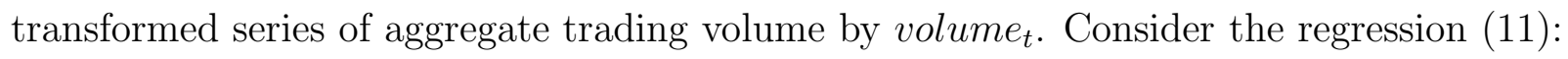

$$
\text { volume }_{t}=b_{0}+b_{1} r_{M, t}+b_{2}\left|r_{M, t}\right|+e_{t}
$$

The test of an asymmetric relationship between market returns and aggregate trading volume is whether $b_{1}$ differs from zero. Variations on this equation are used by Jain and Joh (1988) and Mulherin and Gerety (1988) for hourly aggregate-level relations. (Mulherin and Gerety use a dummy for $r_{M, t}>0$ instead of $r_{M, t}$ itself.) Both find that $b_{1}>0$. Jain and Joh

\footnotetext{
${ }^{8}$ The standard deviations $\sigma_{s}$ and $\sigma_{c}$ are adjusted to keep the volatilities of the sector shocks constant.
} 
find that the 'response' of volume to a given absolute return is 50 percent larger when the market's return is positive $\left[\left(b_{2}+b_{1}\right)\right]$ than when the market's return is negative $\left[\left(b_{2}-b_{1}\right)\right] .^{9}$

An alternative to (11) is to use nonparametric techniques to estimate $\mathrm{E}\left(\right.$ volume $\left._{t} \mid r_{M, t}\right)$, then compare $\mathrm{E}\left(\right.$ volume $\left._{t} \mid x\right)$ with $\mathrm{E}\left(\right.$ volume $\left._{t} \mid-x\right)$. In a working paper, Gallant, Rossi, and Tauchen (1991) construct and display a semi-nonparametric estimate of E(volume $\left.\mid r_{M, t}\right)$ which shows an asymmetric relation between daily aggregate returns and volume: For any given $\left|r_{M, t}\right|$, expected volume is higher when $r_{t}>0 .{ }^{10}$

Prior research proposes three hypotheses to account for the positive relation between stock returns and trading volume. Epps $(1975,1977)$ suggests that there might be behavioral reasons why investors are more willing to trade in rising markets than in falling markets. However, putting into investors' utility functions a greater desire to trade on upticks is not a very satisfactory solution to this puzzle. Another theory that is difficult to incorporate into a model of rational investors is proposed by Harris $(1986,1987)$. He notes that if the expected stock-price change conditioned on the arrival of an arbitrary information 'event' is positive, the arrival of many events (and therefore high volume) corresponds to an increase in the stock price.

A more plausible hypothesis is described in Karpoff (1988), who argues that constraints on short sales raise the costs of trading when stock prices are falling. He tests this hypothesis by examining the correlations between returns and trading volume on various commodity futures contracts, which have no asymmetry in costs for going long versus going short. He finds insignificant correlations for the futures contracts he examines and concludes that the absence of short-sale constraints is the reason. However, at most this evidence indicates that explanations for the positive correlation between stock returns and volume must not be generic explanations applicable to all assets.

\subsection{Explaining trading volume with non-market volatility}

Traders trade on news. When nothing happens in the market, trading is light; when news arrives, both volatility and volume rise. The model of Section 3 suggests that the amount of news is higher on days when the market rises. When the market falls, it is more likely that there is one kind of big news - news about the common shock. When the market rises,

\footnotetext{
${ }^{9}$ Much of the more recent work on the relationship between firm-level volume and stock returns, such as Jones, Kaul, and Lipson (1994) and Chan and Fong (2000), has reversed (11) to put the absolute return on the left-hand-side and volume on the right-hand-side, and dropping the signed return. Because all of the variables are endogenous, the form of the regression largely depends on the research objective. In order to pick up an asymmetric relation between volume and returns, something like (11) is required.

${ }^{10}$ This figure is not in the published version, Gallant, Rossi, and Tauchen (1992); the published version displays $\mathrm{E}\left(r_{M, t} \mid\right.$ volume $\left._{t}\right)$, which contains different information.
} 
it is more likely that multiple news events occurred, causing multiple large sector-specific shocks. Therefore the positive relation between trading volume and the aggregate market return may be the result of a greater flow of information affecting stock prices when the aggregate return is positive than when it is negative.

If this hypothesis is correct, a measure of cross-sectional stock return dispersion should capture much of the explanatory power of the aggregate return in regressions such as (11). To test this hypothesis, trading activity must be measured. I follow Lo and Wang (2000), who advocate the use of turnover (number of shares traded divided by number of shares outstanding). For each common stock listed on the NYSE/Amex/Nasdaq CRSP tape, I compute daily turnover, and then construct a value-weighted measure of average turnover, denoted turnover . $_{\text {. }}$.

To verify the positive relation between trading volume and the return on the market, I first estimate regress turnover on the return to the market, the absolute return to the market, daily dummies, and ten days of lagged variables:

$$
\begin{aligned}
\log \left(\text { turnover }_{t}\right) & =\sum_{j=1}^{5} b_{0, j} D_{i, t}+b_{1} r_{M, t}+b_{2}\left|r_{M, t}\right| \\
& +\sum_{j=1}^{10}\left[b_{2+j} r_{M, t-j}+b_{12+j}\left|r_{M, t}\right|+b_{22+j} \log \left(\text { turnover }_{t-j}\right)\right]+\epsilon_{t}
\end{aligned}
$$

In (12), $D_{i, t}, i=1, \ldots, 5$ are day-of-the-week dummies. The results of estimating (12) over various sample periods are displayed in the first five rows of Table 7 .

Consistent with the idea that news causes both returns and trading, the estimated coefficient on the absolute market return is positive and significant across all time periods. The full-sample results imply that for each percentage point increase in the daily absolute market return, turnover rises by eleven percent. Turnover is also higher when the market goes up. Over the entire 1962 to 1999 period, the coefficient on the market return is 2.6, implying that a day on which the market return rises one percent has 5.2 percent higher turnover than a day on which the market return falls one percent. The subsample periods indicate some instability in this relationship. The largest estimated coefficient is from the 1970s and the smallest is from the 1990s. The relationship is overwhelmingly statistically significant (using heteroskedasticity-consistent standard errors) in all decades except the 1990s.

I now include non-market volatility in the regression to see if it captures the explanatory power of the market return. In results not detailed here, I find that industry-level non-market volatility has relatively little explanatory power for turnover, thus we use only the firm-level 
measure here. The regression equation is

$$
\begin{aligned}
\log \left(\text { turnover }_{t}\right) & =\sum_{i=1}^{5} a_{i} D_{i, t}+b_{1} r_{M, t}+b_{2}\left|r_{M, t}\right|+b_{3} \log \left(\text { FIRM }_{t}\right) \\
& +\sum_{j=1}^{10}\left[b_{3+j} r_{M, t-j}+b_{13+j}\left|r_{M, t}\right|\right. \\
& \left.+b_{23+j} \log \left(\text { FIR }_{t-j}\right)+b_{33+j} \log \left(\text { turnover }_{t-j}\right)\right]+\epsilon_{t}
\end{aligned}
$$

The results of estimating (13) with OLS are displayed in the final five rows of Table 7. There are three main points to take from these results. First, non-market volatility and turnover move closely together. A unit increase in log non-market volatility is associated with an increase in log turnover of 0.8 to 1.0, depending on the subperiod. Second, including nonmarket volatility in the regression reduces substantially the relation between the market's signed return and turnover. In the full sample, the coefficient on the market's return falls by 60 percent when non-market volatility is included. The coefficient remains statistically significant in the full sample and in two of the four decade subsamples. Third, including non-market volatility reduces substantially the coefficient on the absolute market return as well. The coefficient falls by between 60 and 80 percent, depending on the subperiod.

On balance, this evidence supports the hypothesis that the positive relation between aggregate turnover and the market's return is largely driven by the positive relation between non-market volatility and the market's return. This evidence also suggests that much of the

relation between the aggregate turnover and the absolute market return is simply proxying for a relation between aggregate turnover and the amount of firm-level news.

\section{Concluding comments}

This paper has described a strong, positive relationship between the return to the market and the volatility of the non-market components of firms' and industries' stock returns. It also presents a model of skewed return shocks that is consistent with this relationship. An implication of the model is that there is more news when the market rises than when it falls. Since traders trade on news, this explains why trading volume is higher when the market rises.

The results of this paper probably raise more questions than they resolve. First, what are the economic underpinnings of skewed shocks to returns? Campbell and Hentschel (1992) 
have considered this question from the perspective of aggregate shocks and Chen et al. (1999) model cross-sectional variation in negatively-skewed shocks to firm-level returns, but the literature is silent when it comes to understanding positively-skewed non-aggregate shocks. Second, there has been a secular decline in the relationship between non-market volatility and the market's return (both in level and in absolute value). Why are the determinants of non-market volatility becoming decoupled from the determinants of aggregate returns? Third, in the 1990s, the heretofore strong positive relation between aggregate trading volume and the return to the market disappeared. Why? These questions will be the focus of future research. 


\section{References}

Ang, A., and G. Bekaert, 1999, International asset allocation with time-varying correlations, Working paper, Columbia Business School.

Ang, A., and J. Chen, 2000, Asymmetric correlations of equity portfolios, Working paper, Columbia Business School.

Black, F., 1976, Studies of stock price volatility changes, Proceedings of the 1976 Meetings of the Business and Economics Statistics Section, 177-181.

Campbell, J. Y., and L. Hentschel, 1992, No news is good news: An asymmetric model of changing volatility in stock returns, Journal of Financial Economics 31, 281-318.

Campbell, J. Y., M. Lettau, B. G. Malkiel, and Y. Xu, 2000, Have individual stocks become more volatile? An empirical exploration of idiosyncratic risk, Journal of Finance forthcoming.

Chan, K., and W-M Fong, 2000, Trade size, order imbalance, and the volatility-volume relation, Journal of Financial Economics 57, 247-273.

Chen, J., H. Hong, and J. C. Stein, 1999, Forecasting crashes: Trading volume, past returns, and conditional skewness in stock prices, Working paper, MIT.

Das, S., and R. Uppal, 1999, International portfolio choice with systemic risk, Working paper, Harvard Business School.

Davidian, M., and R. J. Carroll, 1987, Variance function estimation, Journal of the American Statistical Association 65, 1509-1526.

Duffee, G. R., 1995, Stock returns and volatility, Journal of Financial Economics 37, 399420.

Epps, T., 1975, Security price changes and transaction volumes: Theory and evidence, American Economic Review 65, 586-597.

Epps, T. W., 1977, Security price changes and transaction volumes: Some additional evidence, Journal of Financial and Quantitative Analysis 12, 141-146.

Erb, C., C. Harvey, and T. Viskanta, 1994, Forecasting international equity correlations, Financial Analysts Journal Nov/Dec., 32-45. 
Fama, E. F., and K. R. French, 1997, Industry costs of equity, Journal of Financial Economics 43, 153-193.

French, K. R., G. W. Schwert, and R. Stambaugh, 1987, Expected stock returns and volatility, Journal of Financial Economics 19, 3-29.

Gallant, A. R., P. E. Rossi, and G. Tauchen, 1991, Stock prices and volume, Working paper, Duke.

Gallant, A. R., P. E. Rossi, and G. Tauchen, 1992, Stock prices and volume, Review of Financial Studies 5, 199-242.

Harris, L., 1986, Cross-security tests of the mixture of distributions hypothesis, Journal of Financial and Quantitative Analysis 21, 39-46.

Harris, L., 1987, Transaction data tests of the mixture of distributions hypothesis, Journal of Financial and Quantitative Analysis 22, 127-141.

Harvey, C. R., and A. Siddique, 1999, Autoregressive conditional skewness, Journal of Financial and Quantitative Analysis 34, 465-488.

Harvey, C. R., and A. Siddique, 2000, Conditional skewness in asset pricing tests, Journal of Finance 55, 1263-1295.

Jain, P. C., and G.-H. Joh, 1988, The dependence between hourly prices and trading volume, Journal of Financial and Quantitative Analysis 23, 269-283.

Jones, C., Kaul, G., and Lispon, M., 1994, Transactions, volume, and volatility, Review of Financial Studies 7, 631-652.

Karpoff, J. M., 1988, Costly short sales and the correlations of returns with volume, Journal of Financial Research 11, 173-188.

Lo, A. W., and J. Wang, 2000, Trading volume: Definitions, data analysis, and implications of portfolio theory, Review of Financial Studies 13, 257-300.

Longin, F., and B. Solnick, 2000, Extreme correlation of international equity markets, Journal of Finance, forthcoming.

Mulherin, J. H. and M. S. Gerety, 1988, Trading volume on the NYSE during the Twentieth century: A daily and hourly analysis, working paper, Securities and Exchange Commission.

Schwert, G. W., and P. J. Seguin, 1990, Heteroskedasticity in stock returns, Journal of Finance 45, 1129-1155. 
Panel A. Industry-level volatility

\begin{tabular}{llllllll}
$\begin{array}{l}\text { Sample } \\
\text { period }\end{array}$ & Obs & Mean & Std. Dev. & Max & Min & $\begin{array}{l}\text { Std. Dev. } \\
\text { of log }\end{array}$ & $\begin{array}{l}\text { AR(1) } \\
\text { of log }\end{array}$ \\
\hline $1962-1999$ & 9441 & 0.0042 & 0.0018 & 0.0321 & 0.0011 & 0.3660 & 0.612 \\
$1962-1979$ & 4385 & 0.0037 & 0.0013 & 0.0163 & 0.0011 & 0.3220 & 0.551 \\
$1980-1999$ & 5056 & 0.0046 & 0.0020 & 0.0321 & 0.0014 & 0.3759 & 0.597 \\
\hline
\end{tabular}

Panel B. Firm-level volatility

\begin{tabular}{llllllll}
$\begin{array}{l}\text { Sample } \\
\text { period }\end{array}$ & Obs & Mean & Std. Dev. & Max & Min & $\begin{array}{l}\text { Std. Dev. } \\
\text { of log }\end{array}$ & $\begin{array}{l}\text { AR(1) } \\
\text { of log }\end{array}$ \\
\hline $1962-1999$ & 9441 & 0.0102 & 0.0025 & 0.0578 & 0.0051 & 0.2276 & 0.869 \\
$1962-1979$ & 4385 & 0.0090 & 0.0021 & 0.0207 & 0.0051 & 0.2188 & 0.875 \\
$1980-1999$ & 5056 & 0.0112 & 0.0024 & 0.0578 & 0.0064 & 0.1803 & 0.816 \\
\hline
\end{tabular}

Table 1: Summary statistics for non-market volatility

Daily industry-level non-market volatility is measured by the value-weighted absolute residual of industries' stock returns. Industry-level residuals are the residuals from regressions of each industry's stock return on the contemporaneous market return and one lag of both the market return and the industry's stock return. Firm-level non-market volatility is measured similarly; the only difference is that the stock return to the firm's industry is added to the regression equation. Returns are in decimal form (e.g., 0.01 is a one percent return). The final two columns report statistics for the logs of the series. 
Panel A. Industry-level volatility

\begin{tabular}{ccccc}
$\begin{array}{c}\text { Sample } \\
\text { period }\end{array}$ & Obs & $\begin{array}{c}\text { Market } \\
\text { Return }\end{array}$ & $\begin{array}{c}\text { Absolute } \\
\text { Market Return }\end{array}$ & RSE \\
\hline $1962-1999$ & 9431 & $\begin{array}{c}3.040 \\
(0.411)\end{array}$ & $\begin{array}{c}14.860 \\
(0.707)\end{array}$ & 0.249 \\
& & 3.431 & 21.982 & 0.228 \\
$1962-1969$ & 1849 & $(0.964)$ & $(1.527)$ & \\
& & 3.473 & 16.711 & 0.233 \\
$1970-1979$ & 2516 & $(0.664)$ & $(1.131)$ & \\
& & 3.880 & 15.786 & 0.271 \\
$1980-1989$ & 2518 & $(0.744)$ & $(1.249)$ & \\
& & 0.891 & 10.397 & 0.250 \\
$1990-1999$ & 2518 & $0.643)$ & $(0.993)$ & \\
& & $(0.643)$ &
\end{tabular}

Panel B. Firm-level volatility

\begin{tabular}{|c|c|c|c|c|}
\hline $\begin{array}{l}\text { Sample } \\
\text { period }\end{array}$ & Obs & $\begin{array}{l}\text { Market } \\
\text { Return }\end{array}$ & $\begin{array}{c}\text { Absolute } \\
\text { Market Return }\end{array}$ & RSE \\
\hline 1962-1999 & 9431 & $\begin{array}{c}1.454 \\
(0.143)\end{array}$ & $\begin{array}{c}8.673 \\
(0.233)\end{array}$ & 0.083 \\
\hline 1962-1969 & 1849 & $\begin{array}{c}2.324 \\
(0.473)\end{array}$ & $\begin{array}{l}11.865 \\
(0.832)\end{array}$ & 0.082 \\
\hline 1970-1979 & 2516 & $\begin{array}{c}1.835 \\
(0.255)\end{array}$ & $\begin{array}{l}10.290 \\
(0.430)\end{array}$ & 0.075 \\
\hline 1980-1989 & 2518 & $\begin{array}{c}1.394 \\
(0.245)\end{array}$ & $\begin{array}{c}9.144 \\
(0.383)\end{array}$ & 0.082 \\
\hline 1990-1999 & 2518 & $\begin{array}{c}0.777 \\
(0.261)\end{array}$ & $\begin{array}{c}5.612 \\
(0.432)\end{array}$ & 0.087 \\
\hline
\end{tabular}

Table 2: The relation between non-market volatility and the return to the market

Daily non-market volatility is measured by the value-weighted absolute residual from a market model regression. The log of non-market volatility is regressed on the contemporaneous return to the aggregate stock market, the absolute value of this market return, and ten lags of market returns, absolute market returns, and log non-market volatility. The table reports the estimated coefficients for the contemporaneous variables. Returns are in decimal form (e.g., 0.01 is a one percent return). Heteroskedasticity-consistent standard errors are in parentheses. Standard errors of the regressions' residuals are reported in the final column. 
Panel A. Industry-level volatility

\begin{tabular}{ccccc}
$\begin{array}{c}\text { Conditioning } \\
\text { variable }\end{array}$ & Obs & $\begin{array}{c}\text { Market } \\
\text { Return }\end{array}$ & $\begin{array}{c}\text { Absolute } \\
\text { Market Return }\end{array}$ & RSE \\
\hline market return $\mid<0.01$ & 7912 & 4.403 & 13.182 & 0.246 \\
& & $(0.613)$ & $(1.051)$ & \\
$\mid$ market return $\mid \geq 0.01$ & 1519 & 2.725 & 13.243 & 0.259 \\
& & $(0.441)$ & $(1.420)$ & \\
\hline
\end{tabular}

Panel B. Firm-level volatility

\begin{tabular}{ccccc}
$\begin{array}{c}\text { Conditioning } \\
\text { variable }\end{array}$ & Obs & $\begin{array}{c}\text { Market } \\
\text { Return }\end{array}$ & $\begin{array}{c}\text { Absolute } \\
\text { Market Return }\end{array}$ & RSE \\
\hline market return $\mid<0.01$ & 7912 & 3.071 & 6.745 & 0.079 \\
& & $(0.199)$ & $(0.338)$ & \\
$\mid$ market return $\mid \geq 0.01$ & 1519 & 1.222 & 9.722 & 0.093 \\
& & $(0.171)$ & $(0.628)$ & \\
\hline
\end{tabular}

Table 3: The relation between non-market volatility and the return to the market, broken down by size of the market return, 1962-1999

The notes to Table 2 describe the measures of volatility and the structure of the regression of $\log$ non-market volatility on various explanatory variables. Here, data from 1962 through 1999 are broken into two samples: days on which the absolute market return is less than one percent and days on which it is at least one percent. The table reports the estimated coefficients for the contemporaneous market return and absolute market return. Returns are in decimal form (e.g., 0.01 is a one percent return). Heteroskedasticity-consistent standard errors are in parentheses. Standard errors of the regressions' residuals are reported in the final column. 


\begin{tabular}{|c|c|c|c|c|}
\hline \multirow[b]{2}{*}{ Statistic } & \multicolumn{2}{|c|}{ Industry-level volatility } & \multicolumn{2}{|c|}{ Firm-level volatility } \\
\hline & Market return & |market return| & Market return & |market return| \\
\hline Mean coef & 3.172 & 16.184 & 2.295 & 8.778 \\
\hline Std. dev. of coef & 7.566 & 13.544 & 2.741 & 4.712 \\
\hline Fraction $>0$ & 0.701 & 0.897 & 0.804 & 0.977 \\
\hline
\end{tabular}

Table 4: The relation between non-market volatility and the return to the market: A summary of small-sample regressions, 1962-1999

The period 7/5/1962 through 12/29/1999 is divided into 214 periods of 44 trading days. For each period, log non-market volatility-measured at both the industry and firm level-is regressed on the contemporaneous return to the aggregate stock market, the absolute value of this market return, and two lags of market returns, absolute market returns, and log nonmarket volatility. The table reports summary statistics for the estimated coefficients on the contemporaneous variables. Returns are in decimal form (e.g., 0.01 is a one percent return). 


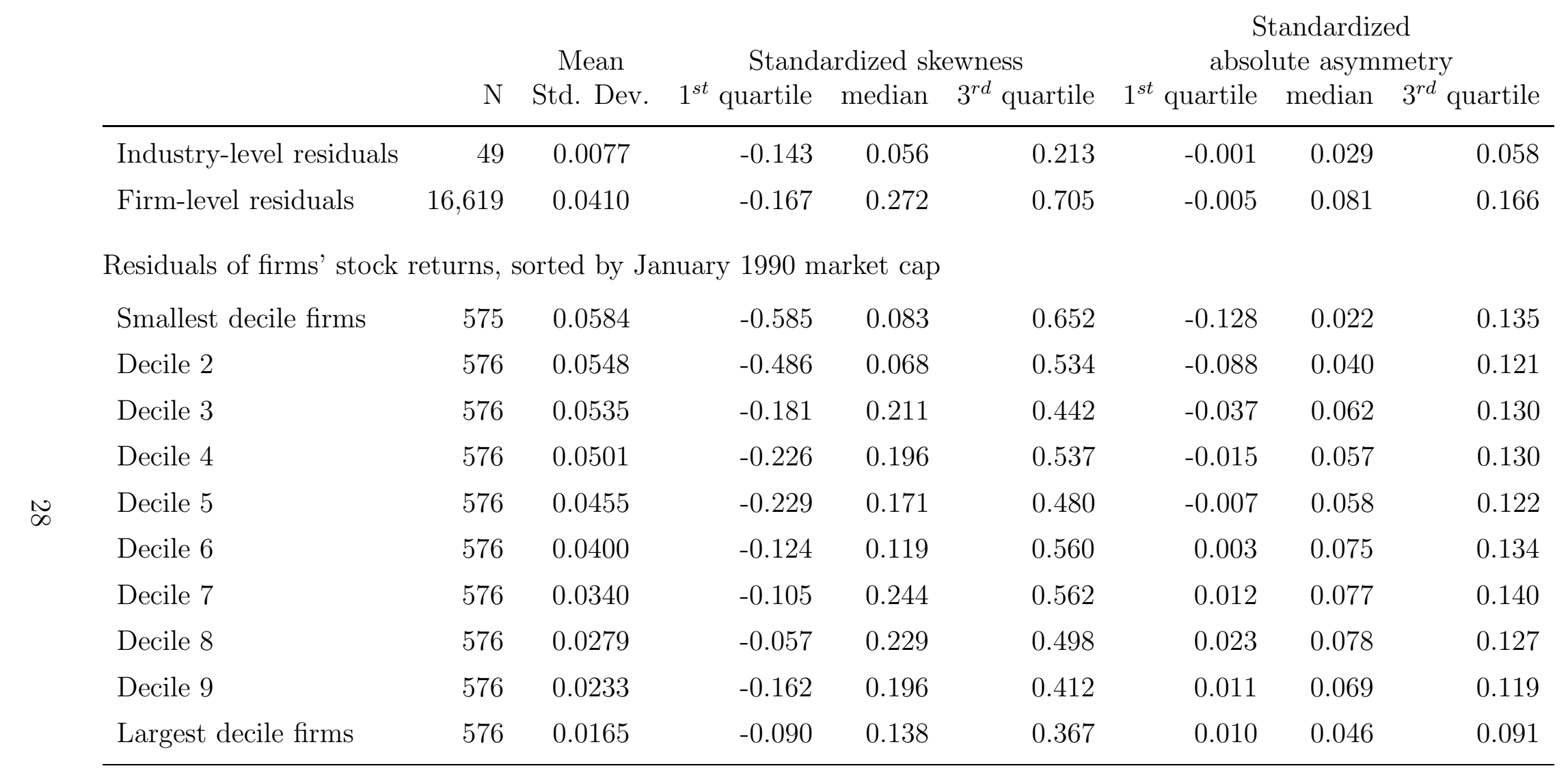

Table 5: Asymmetry in stock return residuals, 1962-1999

Daily industry-level stock-return residuals are from a regression of industry-level stock returns on the return to the contemporaneous CRSP value-weighted index and one lag of returns to both the industry and the CRSP. Firm-level residuals are calculated similarly, but the firm's industry return is included in the regression. Denoting residuals by $\epsilon_{t}$, standardized skewness is $\overline{\epsilon_{t}^{3}} / \sigma_{\epsilon}^{3}$. Standardized absolute asymmetry is $\overline{\epsilon_{t}\left|\epsilon_{t}\right|} /\left(\sigma_{\epsilon} \overline{\epsilon_{t}} \mid\right)$. The number of industries or firms in each group is denoted N. 
Standardized

absolute asymmetry
Mean correlation with market return Market Industry Firm return residuals residuals
Model

\begin{tabular}{lccc}
\hline Actual, 1962-1999 & -0.10 & 0.03 & 0.08 \\
Both types of jumps & -0.11 & 0.03 & 0.07 \\
Only market jumps & -0.11 & 0.00 & 0.00 \\
Only sector jumps & 0.09 & 0.03 & 0.07
\end{tabular}

$\begin{array}{clll}\text { Coef. on market return } & \text { Market return }>0 & \text { Market return }<0 \\ \text { Industry } & \text { Firm } & \text { Industry } \quad \text { Firm } & \text { Industry Firm }\end{array}$

resid vol resid vol returns returns returns returns

returns

\begin{tabular}{llllll}
3.04 & 1.45 & 0.57 & 0.09 & 0.65 & 0.15 \\
2.20 & 1.39 & 0.53 & 0.13 & 0.66 & 0.19 \\
0.13 & 0.09 & 0.53 & 0.13 & 0.66 & 0.19 \\
2.07 & 1.31 & 0.56 & 0.15 & 0.56 & 0.15 \\
\hline
\end{tabular}

Table 6: Simulation results for a model of skewed stock returns

Stock returns for 550 firms in 50 industries are generated by a multifactor model described in Section 3. There is a single common factor and 50 sector-specific factors. Firms are exposed to a single sector-specific factor, but not all firms in a single industry are exposed to the same factor. Depending on the simulation, the factors can have a jump component (positive for sectors, negative for the common factor). The market return is the mean of the industry returns. Industry residuals are calculated using a market-model regression. Firm residuals are calculated by regressing firm returns on both the market return and the return to the firm's industry. Standardized absolute asymmetry is defined in the notes to Table 5. The columns labeled "Coef. on market return" report the coefficient on the market return in a regression of log non-market volatility on the contemporaneous market return and the absolute market return. The final columns report the mean correlation between the market's return and each industry's and firm's return, conditioned on the sign of the market return. 


\begin{tabular}{ccccc}
$\begin{array}{c}\text { Sample } \\
\text { period }\end{array}$ & Obs & $\begin{array}{c}\text { Market } \\
\text { Return }\end{array}$ & $\begin{array}{c}\text { Absolute } \\
\text { Market Return }\end{array}$ & $\begin{array}{c}\text { Firm-level } \\
\text { Volatility }\end{array}$ \\
\hline $1962-1999$ & 9431 & 2.564 & 11.082 & - \\
& & $(0.278)$ & $(0.510)$ & \\
$1962-1969$ & 1849 & 2.826 & 14.069 & - \\
& & $(0.711)$ & $(1.122)$ & \\
$1970-1979$ & 2516 & 3.945 & 12.377 & - \\
& & $(0.474)$ & $(0.763)$ & \\
$1980-1989$ & 2518 & 3.263 & 10.847 & - \\
& & $(0.425)$ & $(0.736)$ & \\
$1990-1999$ & 2518 & 0.315 & 9.135 & - \\
& & $(0.369)$ & $(0.613)$ & \\
$1962-1999$ & 9431 & 1.018 & 4.598 & 0.996 \\
& & $(0.258)$ & $(0.520)$ & $(0.024)$ \\
$1962-1969$ & 1849 & 0.949 & 4.013 & 0.769 \\
& & $(0.742)$ & $(1.205)$ & $(0.047)$ \\
$1970-1979$ & 2516 & 2.012 & 2.110 & 1.038 \\
& & $(0.342)$ & $(0.653)$ & $(0.037)$ \\
$1980-1989$ & 2518 & 1.716 & 2.350 & 1.006 \\
& & $(0.361)$ & $(0.711)$ & $(0.040)$ \\
$1990-1999$ & 2518 & -0.615 & 2.841 & 1.086 \\
& & $(0.367)$ & $(0.637)$ & $(0.055)$ \\
\hline
\end{tabular}

Table 7: Trading volume, the return to the market, and firm-level non-market volatility

The $\log$ of daily value-weighted turnover is regressed on the contemporaneous aggregate market return, the absolute value of this return, the log of firm-level non-market volatility, and ten lags of each of these variables. Non-market volatility is excluded from some of the regressions. Estimated coefficients on the contemporaneous variables are reported in this table. Returns are in decimal form (e.g., 0.01 is a one percent return). Heteroskedasticityconsistent standard errors are in parentheses. 


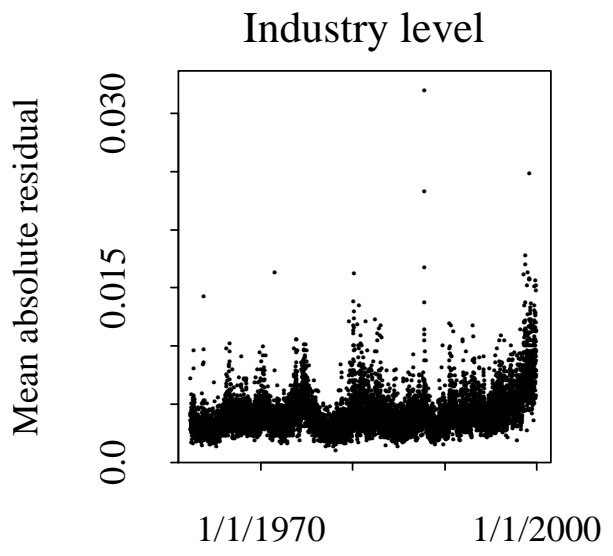

Date

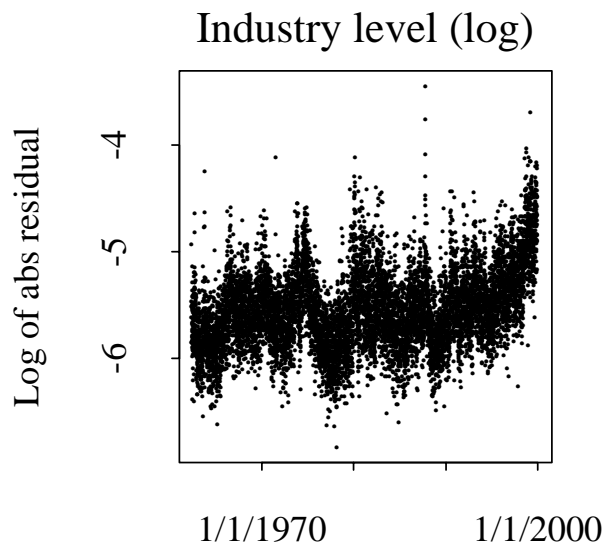

Date

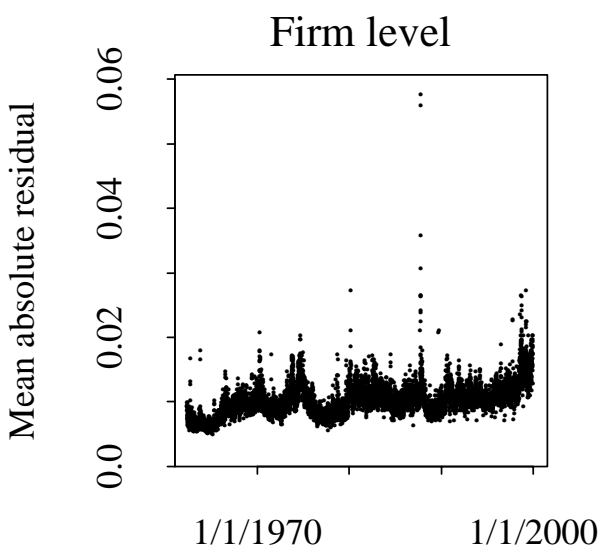

Date

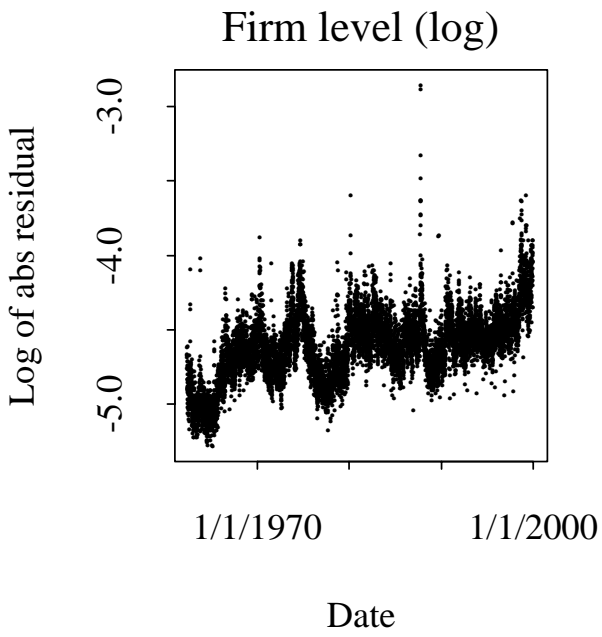

Figure 1: Measures of industry and firm non-market stock return volatility.

Industry-level stock returns are constructed for 49 industries by value-weighting stock returns of firms that belong to the industry. Industry-level daily stock-return residuals are calculated by regressing industry stock returns on the aggregate market return. Day $t$ 's industry-level non-market volatility is measured by the mean (value-weighted across industries) absolute residual on day $t$. Firm-level daily stock-return residuals are calculated by regressing firm stock returns on both the aggregate market return and the firm's industry return. The definition of firm-level non-market volatility follows the industry-level definition. 

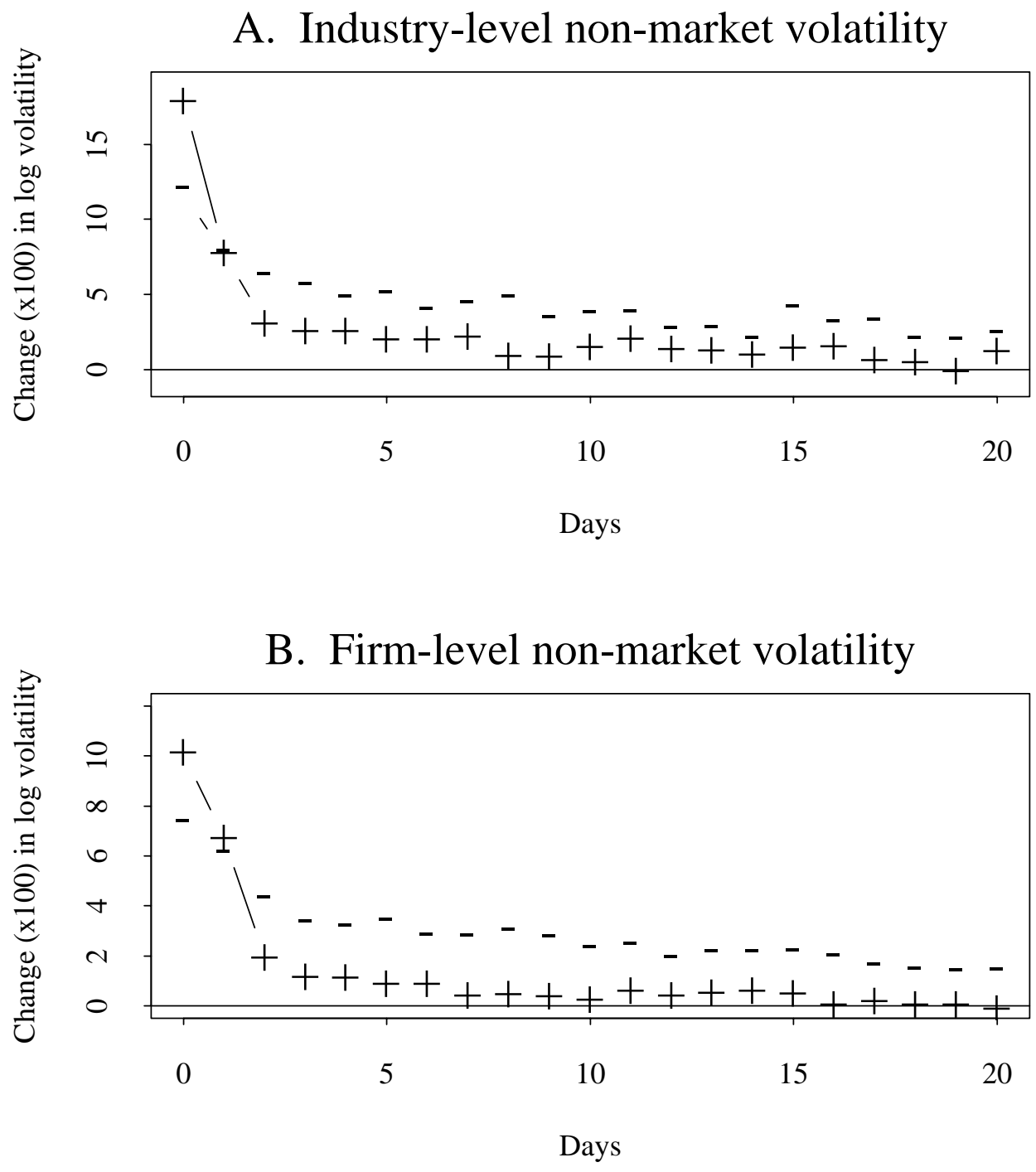

Figure 2: Response of non-market volatility to a stock market absolute return shock.

On day $t=0$, the absolute aggregate market return is assumed to equal one percent. The figure shows the impulse response of non-market volatility if that return is positive (the lines drawn with ' + ') and negative (the lines drawn with '-'). The impulse response coefficients are calculated from regressions of day $t+i \log$ volatility on day $t$ 's market return, absolute market return, and ten lags of all three variables. Regressions are estimated on daily data from 1962 through 1999. 